\title{
On the Cultivation of Innovative and Practical Ability of Contemporary College Students Based on the Theory of "Simile of the Cave"
}

\section{Haiping Zheng and Desheng Zeng}

\begin{abstract}
The position and perspective of viewing problems may determine the extent to which you view the world. The great thinker Plato's famous "simile of the cave" theory just sets out the ideological gully and lead between the stubborn prisoners and the escape of the rope to pursue the light and the truth of the philosophers. This is a major change in the mode of thinking with the eternal ideological charm. In the contemporary, the public entrepreneurship innovation is vigorously advocated, which is the promotion and popularity of innovation practical theories. Establish core value of the socialism because self-confidence in value is the source of cultural confidence, brave exploration of truth and even the re-understanding and highly clearance of the real world as well as the insistence on the value. Then, it is of great significance to transform the self-styled thinking mode for innovative practice and thinking.
\end{abstract}

Keywords: Theory of "simile of the cave"; Investigation; Innovative practice; Confidence in value; Thinking mode

\section{基于 “洞喻” 理论的固执与侦查反思当代大学生 创新实践能力的培养}

\author{
郑海平 曾德生 \\ ( 景德镇陶瓷大学，江西 景德镇 333000 )
}

摘要: 看待问题的立场与角度, 可能决定了你看清这个世界的程度。伟大思想家柏拉图著名的“洞喻”理论恰恰阐明 了固执自闭的捆绑囚徒和挣脱绳索追求光明与真理的哲学侦查者之间的思想沟餐与引领。这是思维模式的重大转变, 具有 永恒的思想鬼力, 在当代, 大力倡导大众创业万众创新, 是创新实践理念的推广与普及, 树立社会主义核心价值观, 价值 观自信是文化自信的源头, 对真理的勇敢探索, 更是对现实世界的再认识, 高度澄清与坚守价值观, 那么转化固步自封的 思维模式为创新实践理念具有重大意义。

关键词: “洞喻”理论 侦查 创新实践 价值观自信 思维模式

中图分类号: G640 文摘标识码: A

引言

决策专家朱莉娅. 加莱夫表示，你是一个士兵还是侦查员？你的回答可能决定了你看清这个世界的程 度。她强调知性决定一切, 特别是在审视自己的信仰时。这与柏拉图著名的 “洞喻” 理论有异曲同工的 辉映, 都是强调知性实践与真理探求的重大意义, 都是重在思维立场的转换模式, 这对于探讨创新实践 理念的培养有巨大的参考借鉴意义。

\section{1. “洞喻” 理论的内涵与解读。}

\section{1 “洞喻” 理论的内涵}

在柏拉图的《理想国》中, 有一个著名的洞穴比喻来解释理念论：有一群囚犯在一个洞穴中, 他们 手脚都被捆绑, 身体也无法转身, 只能背对着洞口。他们面前有一堵白墙, 他们身后燃烧着一堆火。在 
那面白墙上他们看到了自己以及身后到火堆之间事物的影子, 由于他们看不到任何其他东西, 这群囚犯 会以为影子就是真实的东西。最后, 一个人挣脱了枷锁, 并且摸索出了洞口。他第一次看到了真实的事 物。他返回洞穴并试图向其他人解释, 那些影子其实只是虚幻的事物, 并向他们指明光明的道路。但是 对于那些囚犯来说, 那个人似乎比他逃出去之前更加愚蚌, 并向他宣称, 除了墙上的影子之外, 世界上 没有其他东西了。

\section{2 “洞喻” 理论的解读}

“洞喻” 理论的阐述的群体是一群共命运的囚犯和一个挣脱绳索的侦查者传播引领者。囚犯眼前接 受的都是同样的狭窄面, 他们同样有着固定的思维模式, 以为白墙上的一切就是全世界, 就是事物的全 部与真实, 直到终老, 蒙蔽视听, 扼杀真理; 而侦查者挣脱绳索便是巨大的思维救赎, 他向往更加全面 的视野和对未知世界的探索, 这便是思维创新; 他敢于转身, 敢于走出洞口, 这便是创新实践的勇气与 行动; 他看到光明与真实的世界后, 返回洞中, 向囚犯们讲述外面的世界并试图帮他们揭开绳索带出山 洞, 这便是真理的传播与思维的引领, 这不仅是哲学家的责任重担, 大众也同样应该努力创新探索, 接 受真理, 树立正确的价值观, 尤其当代大学生。

\section{2. 剖析当代大学生思维模式的现状}

\section{1 当代大学生的 “固执”}

2.1.1 固执地自闭状态, 拒绝接受外部信息, 拒绝接触外部人群, 沉醉在自己的网络世界里;

2.1 .2 固执地蒙蔽试听, 这是偏执的自信与自负, 不虚心接受别人的建议与忠告, 对自己以外的世界 和观点持怀疑和冷眼旁观的态度;

2.1 .3 固执地只接受灌输式教育, 这与中国传统教育模式和应试教育有很大关系, 中国传统观念中的 “和” 与现在大力弘扬的 “创” 存在辩证统一的关系, “和” 是一种为人处事的态度, “创” 是一种思 维和行动上的突破, 两者是和和共生相对相伴的关系, 亦同继承和发展的关系。

2.1.4 固执地自我信仰, 当代大学生缺乏榜样意识, 理想信念不坚定, “我只崇拜我自己”, 这是关 注自我的自信, 也是难以虚心踏实学习实践的心理门槛。

\section{2 当代大学生的 “侦查”}

2.2 .1 实现了侦查的第一步： “松绑” : 这是信息化高度发达, 无法阻拦信息的时代, 大部分大学生 在接受第一课堂灌输式教育的同时, 也通过网络和手机进行信息采集和知识搜索, 这是一大进步, 实现 了从第一课堂到第二课堂的第一步;

2.2.2 欠缺侦查的第二步: “转身” : 学生不主动学习, 浮躁应对, 知识基础不牢, 不主动进行知 识拓展和实践演练, 第二课堂处于空白和无所适从的状态; 对于大学生活的评价, 大部分大学生觉得有 些堕落了, 只有少部分觉得充实有了明确的方向。

2.2 .3 欠缺侦查的第三步：“探索” : 大部分在校大学生没有实践探索意识, 或者盲目实践, 只求 赚取零用钱, 对于专业的创新性实践意义不大。普遍觉得提升专业技能和社会实践能力才是重中之重, 但真正毕业后创新创业的比例却不足 $10 \%$; 创新成果贫乏: 局限于毕业实习的过渡性实践, 自主实践理 念欠缺, 学生不重视创新实践活动; 创新技能不强, 存在设计能力不足, 操作能力差, 表达能力不强的 情况。 
2. 2.4 欠缺侦查的第四步： “引领” : 理想与信念意识淡薄, 为理想而努力, 为信念而坚守的越来 越少, 或金钱意识至上, 工作为油盐, 或无欲无求, 消磨时光, 躲避竞争, 自闭清净, 或实践无计划, 思维不启动, 忙忙碌碌, 碌碌而无为。对于理想和价值观的调查中, 出现了多样化的选择, 按照理想信 念去追求的仅占 $15 \%$; 榜样力量欠缺, 目前主要存留在学生干部在学校活动中的发动作用。

\section{3. 以当代大学生思维转变的必要}

大学生是祖国的未来和希望, 是社会发展的储备力量, 当代青年的价值取向决定着整个社会的价值 走向, 当代大学生的思维创新力决定着社会发展的引擎和驱动力。为引导当代大学生成长, 在实践中探 索大学生德育的新路径, 引导思维的大胆突破和创新实践的探索具有重大意义。

\section{3. 创新实践能力的培养途径}

据调查显示, 对大学生价值观和思维定式形成的影响因素上, $50 \%$ 来源于家庭, $35 \%$ 来源于学校, $12 \%$ 来源于榜样，剩下的 $13 \%$ 来源于书本。在书籍阅读方面，专业书籍只占 $30 \%$ 左右。

\section{1 家庭教育}

\section{1.1 良好家风家规的继承与弘扬}

家庭教育对当代大学生思维观念的影响是最为深入和广泛的, 每一个大学生都接受学校统一的教 育, 但每个学生又来自各个不同的家庭, 彰显这每个家庭的性格特征和处事方式。虽然家规的概念已经 慢慢淡化，但良好的家规是中华民族优秀文化的缩影，是价值观的家庭式体现，家庭教育持续而深远， 坚持弘扬良好的家规家风有利于促进当代大学生正确价值观的树立，有利于正确思维模式的形成。

\section{1.2 良好家庭氛围的塑造}

良好的家庭氛围是家庭成员共同努力的结果, 父母的和谐相处, 对于孩子的身心健康和社会幸福感 的提升具有重要意义。1、环境氛围：2、情感氛围 3、父母人格氛围; 4、文化氛围; 父母无论在工作、婚 姻和德育上都起到了榜样力量。家庭氛围的活跃与沉闷直接影响着孩子思维的形成与转化速率。

\section{1 .3 父母教育理念转变—— “放手”}

精神和物质上支持孩子创新创业, 倾听孩子的独特见解, 尊重孩子的自由发展, 家庭是社会的无数 个单元, 起着基础的作用, 家庭的教育理念能否与社会大力倡导的创新理念和实践理念相适应, 决定着 孩子适应社会的能力。第一、言传身教胜过千言万语; 第二、不需扬鞭自奋蹄一一给一个孩子选择的自 由、发展的空间；第三、做到因材立志，因材为学，因材施用。

\section{2. 学校教育}

3.2. 1 学习实践: 师生角色转换: 学生上讲台, 老师测评指导;

老师 “放手” , 改灌输式教育为引领式指导; 学生 “手眼脚” 并用, 改受教为自行探索求老师指 导, 学生跑图书馆查阅资料, 提出个人见解, 布置实践任务, 学生完成实践报告; 在人才培养计划、课 程体系、教学内容、教材建设和教学方法与手段等方面进行全方位的创造性改革, 形成鲜明的特色。

3.2 .2 创新实践: 鼓励学术创新, 技术创新和创新创业;

提高创新基地建设水平, 保证学科专业覆盖面, 以创新教育为主, 兼顾创业教育, 极开设创新创业 教育课程, 积极开展创新创业实践 (大一年度项目、大创计划、创新创业竞赛、科研项目、发表论文、申 请专利）鼓励学科交叉，培养学生创新创业和团队合作能力。 
3.2.3 社会实践: 学生要开展好第二课堂的规划, 老师做好第二课堂的指导;

支持鼓励学生社团活动，培养学生骨干，策划有水平，有明确培养目标和培养计划的实创新践项 目; 鼓励学生创新创业, 做好职业规划和心理辅导。

\section{2 .4 青年马克思主义者的培养}

高校是实施 “青马工程” 的基础性主阵地。截至目前, 已有 1000 余所高校根据自身的办学特色和学 生实际设立了培养载体。中国人民大学的青年先锋训练营、南京大学的青年共产主义学校、浙江大学的 青年马克思主义学院、中山大学的 “青马学堂” 等, 成为高校培养青年马克思主义者的有形载体和有效 途径。遵循科学规律, 引导帮助青年学生骨干对党的科学理论学而信、学而用、学而行创新培养路径, 提升青年学生骨干的理论自觉和理论自信加强研究宣讲, 促进党的科学理论在青年学生中的传播。

\section{3. 社会引领}

3. 3.1 社会主义核心价值观的弘扬

用知行合一的理念来培育和弘扬社会主义核心价值观, 需要遵循其内在的发展逻辑和生成规律, 在 “知、信、行、成” 四个字上聚焦, 形成知而信、信而行、行而成的衔接递进、互动共进的良好局面。 “知” : 解决好 “知道和理解” 问题 “信” : 解决好 “信守和认同” 问题 “行” : 解决好 “行动和融 入” 问题 “成” : 解决好 “成效和落实” 问题。

\section{3.2 中国传统文化的继承与发展}

中国优秀的传统文化只有得到充分的继承，才可以从中汲取创新的养分，没有无根据的创新，每一 个创新都是在继承的基础上促进文化的发展。中国在全球设立孔子学院, 而中国当代大学生却崇拜西方 节日与文化而冷落了中国传统，应该烘托中国传统文化的传播的气氛，让每一个中国大学生真正了解国 情, 继往开来, 开拓创新。

\section{3.3 大力倡导大众创业万众创新}

各个高校在提高就业率的同时，也应把创业率提上重要日程。以江西省特色高校景德镇陶瓷大学为 例, 陶瓷类相关专业为主打专业, 大部分毕业生投入到陶瓷行业大军中，还有一部分陶艺专业的学生， 侧重手工制作, 景德镇艺术氛围浓厚, 是创作创业佳地, 学校积极鼓励和促进学生创新创业, 专业老师 做创业规划和指导，续写着景德镇陶瓷艺术的新篇章。

\section{参考文献}

1. 李长伟. 重读洞穴之喻之中的公民教育 $[J]$. 内蒙古师范大学学报 (教育科学版). 2008 年 01 期.

2. 陈雅萱. 新媒体环境下增强高校思想政治教育的实效性路径研究 [J]. 青年与社会. 2013.

3. 李涛. 张立红. 陈吉明. 创新与创业课程体系的构建研究 [J]. 洛阳理工学院学报: 社会科学版. 2009.

4. 潘禁元. 走向 21 世纪高等教育思想的转变. 高等教育研究. 1999. 01.

5. 王俊凯. 网络时代下的大学生第二课堂教育. 河北大学学报(哲学社会科学版). 2003. 03.

\section{作者简介：}

郑海平 (1984一), 女, 山东德州人, 景德镇陶瓷大学, 在读研究生, 主要研究方向:马克思主义哲学

曾德生（1968一)，男, 江西瑞金人, 厦门大学教育研究院博士生, 景德镇陶瓷大学教授, 硕士生导师, 主要研究方 向: 马克思主义理论/思想政治教育。 


\section{References:}

[1] Li Changwei. Re-interpretation of Civic Education in the Simile of the Cave [J]. Journal of Inner Mongolia Normal University (Education Science Edition). 2008.01.

[2] Chen Yaxuan. A Study on the Practical Path of Strengthening Ideological and Political Education in Colleges and Universities under the New Media Environment [J]. Youth and society. 2013.

[3] Li Tao, Zhang Lihong, Chen Jiming. Research on the Construction of Innovation and Entrepreneurship Curriculum System [J]. Journal of Luoyang Institute of Technology (Social Science Edition). 2009.

[4] Pan Maoyuan. Transformation of the Thought of Higher Education in the 21st Century. Higher Education Research. 1999.01.

[5] Wang Junkai, The Second Classroom Education of College Students in the Network Era, Journal of Hebei University (Philosophy and Social Sciences), 2003.03 